Research Paper:

\title{
The Effects of E-Learning on Patient Safety Culture in Emergency Nurses
}

Tahereh Najafi Ghezeljeh $^{1}$ (D), Razieh Karimpour ${ }^{1 *}$ (D), Soghra Omrani ${ }^{1}$ (D), Shima Haghani ${ }^{1}$, Azita Emami ${ }^{2,3}$

1. Nursing Research Center, Iran University of Medical Sciences, Tehran, Iran.

2. Biobehavioral Nursing \& Health Systems, School of Nursing, University of Washington, Seattle, WA, USA.

3. Department of Neurobiology, Care Sciences and Society, Division of Nursing, Karolinska Institute, Huddinge, Sweden

\begin{tabular}{|c|}
\hline $\begin{array}{l}\text { dtation: Najafi Ghezeljeh, T., et al. 2021. The Effects of E-Learning on Patient Safety Culture in Emergency Nurses. Journal } \\
\text { of Client-Centered Nursing Care, 7(3), pp. 215-226. https://doi.org/10.32598/JCCNC.7.3.378.1 } \\
\text { dol'https://doi.org/10.32598/JCCNC.7.3.378.1 }\end{array}$ \\
\hline
\end{tabular}

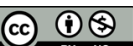

Article info:

Received: 29 May 2021

Accepted: 15 Jul 2021

Published: 01 Aug 2021

Keywords:

Patient safety, Culture, Learning, Distance learning, Emergency Nursing

\section{A B S T RA C T}

Background: Patient Safety (PS) is a priority for all healthcare organizations. Instilling best practices is necessary for PS improvement. This study assessed the effects of Electronic Learning (e-learning) on PS culture among emergency nurses and nursing managers.

Methods: This quasi-experimental study was conducted in March-August 2020 using a two-group pre-test, post-test non-randomized design. The study subjects included 69 nurses who were selected from the emergency rooms and 20 nursing managers of two hospitals in Qazvin City, Iran. They were recruited to the study through census and were non-randomly allocated to either an e-learning or a comparison group. The comparison group received PS-related education through two 1.5-hour lectures on two consecutive days. The experimental group received PS training through a 15-part online course in two months. PS culture was assessed before and 3 months after initiating the intervention. The necessary data were collected through the self-report method using a demographic data questionnaire and the Hospital Survey on Patient Safety Culture (HSOPSC) questionnaire. The obtained data were analyzed by Chi-squared test, Fisher's Exact test, Independent-Samples t-test, Paired-Samples t-test, and Analysis of Covariance (ANCOVA) in SPSS.

Results: The pre-test mean score of PS culture in the e-learning group was significantly less than that in the comparison group $(\mathrm{P}=0.002)$. The mean score of PS culture significantly increased in both research groups after the intervention $(\mathrm{P}<0.05)$. Besides, the post-test mean score of PS culture in the e-learning group was significantly greater than that in the comparison group $(\mathrm{P}<0.001)$

Conclusion: E-Learning is more effective than conventional lecturing in improving PS culture among emergency nurses. This method is suggested to be used as an effective approach to PS culture improvement among emergency nurses.

\footnotetext{
* Corresponding Author:

Razieh Karimpour

Address: Nursing Research Center, Iran University of Medical Sciences, Tehran, Iran.

Tel: +98 (21) 88201978
}

E-mail: leiladaneshpajooh@yahoo.com 


\section{Highlights}

- E-Learning significantly improved patient safety culture and all its components, except for the frequency of-events reporting- dimension.

- The e-learning program provided the examined nurses with the opportunity to frequently review educational materials, answer evaluation questions, and receive relevant feedback.

- A part of the positive effects of e-learning on patient safety culture among emergency nurses can be attributed to the inclusion of nursing managers in this study.

\section{Plain Language Summary}

E-Learning enables learners to access educational materials at any time and place. It can be used as an effective method for providing in-service training to nurses. It does not necessitate the physical presence of learners in a certain place at a specific time. E-Learning can thus be used to provide in-service training during epidemics and pandemics, like the current coronavirus pandemic without exposing learners to the risk of infection. According to the present study results, e-learning improved patient safety culture among emergency nurses and nursing managers. Nursing managers and hospital supervisors should improve nurses' understanding of the importance of error reporting, and create a supportive environment to encourage them to report their errors without the fear of negative consequences.

\section{Introduction}

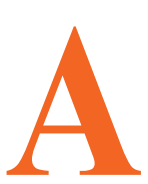

tient safety (PS) is defined as the absence of preventable harm to a patient during the process of healthcare and reduction of the risk of unnecessary harm associated with healthcare to an acceptable minimum (Vincent 2011). Ensuring PS is necessary to conform with the ethical principle of nonmaleficence (Stang et al. 2018); thus, it is a professional and ethical responsibility of all healthcare providers (González-López et al. 2017).

World Health Organization (2019) reported that each year, 42.7 million traumatic events occur among the 421 million patients who are hospitalized in clinical settings. The Canadian Institute for Health Information (Chan et al. 2016) estimated that 30000 preventable injuries have happened in 138000 hospitalizations in Canada in 20142015. The overall prevalence of medical errors during different phases of healthcare delivery is approximately 7.5\% (Bodur et al. 2010). There exists inaccurate and unreliable statistics in Iran. However, a study in the intensive care units of hospitals affiliated to Yazd University of Medical Sciences, Iran, indicated that about $67 \%$ of nurses had a medication error during the last 6 months; approximately $7 \%$ of them had at least one error (Bagheri et al. 2021).
The lack of adherence to PS has numerous unpleasant consequences, including patient harm and death, increased healthcare costs, and the necessity of deploying other healthcare resources (Slawomirski et al. 2017). The frequency and impact of medical errors have been extensively documented. The WHO estimated that millions of individuals annually die or experience injury or disability due to PS problems, globally (Lawati et al. 2018). The PS-induced problems were the fifth leading cause of death in 2010 (Bodur et al. 2010) and the 14 ${ }^{\text {th }}$ leading cause of death in 2018 (Vincent 2011). The Institute of Medicine reported that human errors in the healthcare system are responsible for $>98000$ deaths and more than one million injuries in the United States annually; most of which are preventable (Boamah et al. 2018). Accordingly, one out of every 18 hospitalized patients experienced at least one preventable injury (Chan et al. 2016).

Emergency Departments (EDs) are a unique and challenging healthcare environment. EDs provide 24/7 emergency care and commit to providing safe and high-quality healthcare (Lambrou et al. 2015). ED is characterized as a high-risk location concerning medical errors, i.e., defined as a failure made in the caring process that results in, or has the potential to harm patients (källberg et al. 2017). The rate of medical errors in the ED is high due to high workload, overcrowding, patient complexity, staff fatigue, and the lack of staff (O'Connell et al. 2018; Sin et al. 2018). Making improvements in PS requires that staff be involved in efforts to increase the awareness of PS risk factors and 
identifying strategies that facilitate the maintenance of PS in high workload times (Kallberg et al. 2017).

Harm prevention was associated with developing a strong PS culture (Alswat et al. 2017; Elmontsri et al. 2017). To improve PS, the first step is understanding the safety culture of an organization (Lawton et al. 2017). The concept of safety culture as part of organizational culture is thought to form a basis for the safe delivery of highquality healthcare (Hogden, Churruca \& Bierbaum 2017).

An effective safety culture requires an environment that encourages collaboration, quality, and safety (Rice et al. 2018). In a safety culture, priority is placed on developing procedures, expectations, attitudes, and behaviors that enhance PS. Such a culture serves as the foundation for improving technical and socio-adaptive aspects of care to enhance safety (Meddings et al. 2017). It positively affects interventions that improve the patient's health (Campione \& Famolaro 2018) and the quality of healthcare. A PS culture fosters learning from errors, greater cooperation and respect, better relationships with healthcare providers, and ultimately better system performance (Nordin et al. 2020).

In a literature review on PS culture assessment in hospitals using the Hospital Survey of Patient Safety Culture (HSOPSC) questionnaire, articles published from 2005 to July 2016 in English were explored. Accordingly, Portuguese and Spanish and those indexed by PubMed, Science Direct, and Scopus were included. Evaluating 33 articles from 21 countries indicated that the organizational culture of hospitals is usually underdeveloped or poor. Inadequate safety culture is recognized as an essential factor for adverse consequences. Besides, there is a need to strengthen PS initiatives (Reis et al. 2018). Maintaining a safety culture requires leaders who support and promote safety measures (Campione \& Famolaro 2018).

PS education for healthcare providers, particularly nurses, is a potentially effective strategy for PS improvement (Pakzad et al. 2016); however, careful consideration must be given to the mode of education.

The lecture is a traditional method of education (Nasiri et al. 2015). It is simple to use and inexpensive. Using audiovisual content during the lecture in recent years has increased the effectiveness of this method. The question and answer method can also be used during a lecture to improve learners' engagement in the process (Mollazadeh et al. 2014). However, the lecture method has several limitations, particularly for non-students. The lecture takes place at a specific time and location, i.e., uncon- trolled by the learner. Furthermore, it cannot be repeated for clarification, and dissemination is limited to the number of individuals a classroom or other facility can accommodate (Keis et al. 2017). The recent Coronavirus Disease 2019 (COVID-19) pandemic has increased the risk of infection from learning within the confines of a classroom

E-Learning is another option for education. It has two main components of content and technology. It consists of a cognitive process that enables knowledge acquisition through technology (Aparicio, Bacao \& Oliveira 2016). E-Learning offsets some of the disadvantages present in lecture learning. With e-learning, there is no constraint on when or where a subject receives instruction, the portions of the material can be easily reviewed, an infinite number of individuals can be accommodated, and the cost per learner is lower.

As a result, e-learning is a particularly appropriate method for nursing professionals with limited time for learning. E-Learning helps learners control the pace and place of their learning. This is because they do not need to be in a certain physical environment at a specified time (Pham et al. 2019). E-Learning is also an easy-to-use, feasibly accessible, and flexible method that provides learners with the opportunity to access educational materials even after the end of formal education (Meredith et al. 2018). E-Learning enables learners to personally take the responsibility of learning (Wilkerson et al. 2012). There are some limitations to e-learning, including the need to use a computer or mobile phone to access materials that may, financially or technically, impede some individuals' abilities to acquire knowledge (Sheikhaboumasoudi et al. 2018). Teacher-student communication is poor in e-learning, i.e., because of a lack of face-to-face interaction (Shorey et al. 2018).

Numerous studies have assessed the impact of PS education on nurses. A study on Jordanian nurses found that training helped increase error reporting, reduce reprehensible attitudes toward nurses who reported their errors and improve their PS culture (AbuAlRub \& Abu Alhijaa 2014). A study in Iran reported that education through both lecture and e-learning significantly improved PS culture among nursing managers; although the benefits of the lecture were significantly greater than that of e-learning (Mahmodi Shan et al. 2019). Another study in Iran found that although both lecture and e-learning significantly improved PS culture among nurses, the effects of e-learning were significantly greater (Pakzad et al. 2016). 
A literature review including 2491 nurses and nursing students also reported no significant difference between the benefits of e-learning and lecture and recommended further studies (Lahti, Hätönen \& Välimäki 2014). Another review that compiled data from 52 studies with a total sample of 12294, conducted between 2007 and 2017, concluded that e-learning has positive effects; however, they recommended further studies because most reviewed studies were restricted to medical education and high-income countries by using the measurement instruments of unknown validity and reliability (Barteit et al. 2020). The findings of studies in high-income countries are not easily generalizable to low- or middle-income countries (WHO 2015).

The available contradictory results on the impact of elearning on PS culture highlight the necessity of further studies in this area. The present study aimed to determine the effects of e-learning on PS culture among emergency nurses.

\section{Materials and Methods}

This quasi-experimental study was conducted in MarchAugust 2020 using a two-group pre-test, post-test nonrandomized design. All 112 nurses and nursing managers in Shahid Rajaei and Velayat Hospitals, Qazvin City, Iran, were invited to participate in this research. The inclusion criteria included a BA or higher in nursing, work experience of $>6$ months in the ED for nurses and in the hospital nursing office for managers, and the ability to use a smartphone or computer.

The subjects were excluded if they changed their workplace during the study, had an initial PS culture score $>75 \%$, or if they provided an incomplete main study instrument. All nurses from one hospital were allocated to the e-learning (intervention) group and all nurses from the other hospital were allocated to the lecture (comparison) group.

The required sample size was calculated with a confidence interval of 0.95 and a power of 0.80 ; with the supposition that e-learning should improve the PS culture score in comparison with the lecture group by 10 points to be considered statistically significant. The sample size calculation (Equation 1) presented that a minimum of 40 subjects per group was needed.

Equation 1. Sample size calculation formula:

1

$$
\begin{aligned}
& n=\frac{\left(Z_{1-\alpha / 2}+Z_{1-\beta}\right)^{2}\left(\sigma_{1}^{2}+\sigma_{2}^{2}\right)}{d^{2}} \\
& =n=\frac{(1.96+0.84)^{2}\left(15.5^{2}+17.5^{2}\right)}{10^{2}}=40
\end{aligned}
$$

The necessary data were collected through the self-report method using a demographic data questionnaire and the Hospital Survey on Patient Safety Culture (HSOP$\mathrm{SC})$ questionnaire. The items of the demographic questionnaire were age, gender, marital status, educational level, clinical work experience, work experience in the ED, employment status, work shift, and history of attending PS-related educational courses in the past year.

The HSOPSC is a 42-item questionnaire (Rockville et al. 2016) with 12 dimensions, including the frequency of events reported ( 3 items), the overall perceptions of PS (4 items), supervisor/manager expectations, and actions promoting PS (4 items), organizational learning/ continuous improvement (3 items), teamwork within departments (4 items), communication openness (3 items), feedback and communication about errors (3 items), non-punitive response to error (3 items), staffing (4 items), hospital management support for PS (3 items), teamwork across hospital departments (4 items), as well as hospital handoffs and transitions (4 items). Positively worded items are scored from 1 (completely disagree) to 5 (completely agree); however, negatively worded items are scored in reverse. For scoring, the percentage of positive responses is calculated. Positive responses are the "completely agree" and the "agree" responses of the positively-worded items as well as the "completely disagree" and the "disagree" responses of the negativelyworded items. The HSOPSC measures the culture of PS at a single hospital in a specific location (Rockville et al. 2016). We scored positive responses 1 and negative responses zero and the percentage of positive responses was calculated. Previous studies reported that the Cronbach's alpha coefficient of this survey was equal to 0.810.889 (Zhao et al. 2017; Mohebbifar \& Alijanzadeh. 2015; Amiri et al. 2018). The relevant Cronbach's alpha coefficient in this study was measured to be 0.868 . Both research groups completed this questionnaire before and 3 months after initiating the study intervention.

The content of the educational program was developed using clinical guidelines and the existing literature and included materials on PS, its different aspects (i.e., medication error, hemovigilance, pressure ulcer, fall, nosocomial infections, hand hygiene, surface $\&$ equipment disinfection, \& waste management), PS culture, the effects of human factors and teamwork on error incidence, the importance of communication with patients before and after errors and giving appropriate feedback about errors, root cause analysis of errors, activity analysis after an adverse event, and risk management. 
The content validity of the educational program was approved by a panel of 3 experts in nursing. The educational program for participants in the e-learning group consisted of 15 modules, i.e., created using Storyline. Each part lasted 10-20 minutes. The whole program lasted 250 minutes. Each part contained text, graphics, audio clips, and questions with feedback for evaluating the content. The study participants had an opportunity to repeat answering the questions. Every 4 days during the study, the electronic content of one part was uploaded to the website of the study setting and its link was provided to the e-learning group. They could download and use the content offline, at their convenience. The e-learning intervention lasted two months. Each week, the research participants received a message via social media reminding them to study the content; any questions were answered via social media.

The comparison group received the same content through two 1.5-hour lectures presented on two consecutive days. After the post-test, the links of the e-learning program were provided to these participants as an ethical consideration.
The obtained data were analyzed using SPSS. The Chisquared test, Fisher's Exact test, and Independent-Samples t-test were used for between-group comparisons regarding categorical and numerical variables at pre-test. The Analysis of Covariance (ANCOVA) was used for between-group comparisons concerning the post-test values of PS and its dimensions adjusted for their corresponding pre-test values. The eta-squared value $\left(\eta^{2}\right)$ in the ANCOVA suggested the effect size and was interpreted as follows: 0.01=small effect size; $0.06=$ medium effect size; and $>0.14=$ large effect size (Cohen 2013). Within-Group comparisons were also performed using the Paired-Samples t-test. The significance level was set at $<0.05$.

\section{Results}

A total of 112 nurses were initially recruited and allocated to two 56-subject study groups. Fourteen participants from the comparison group and 9 from the e-learning group were excluded from the study for the following reasons: voluntary withdrawal, maternity leave, changing their wards and providing incomplete answers to

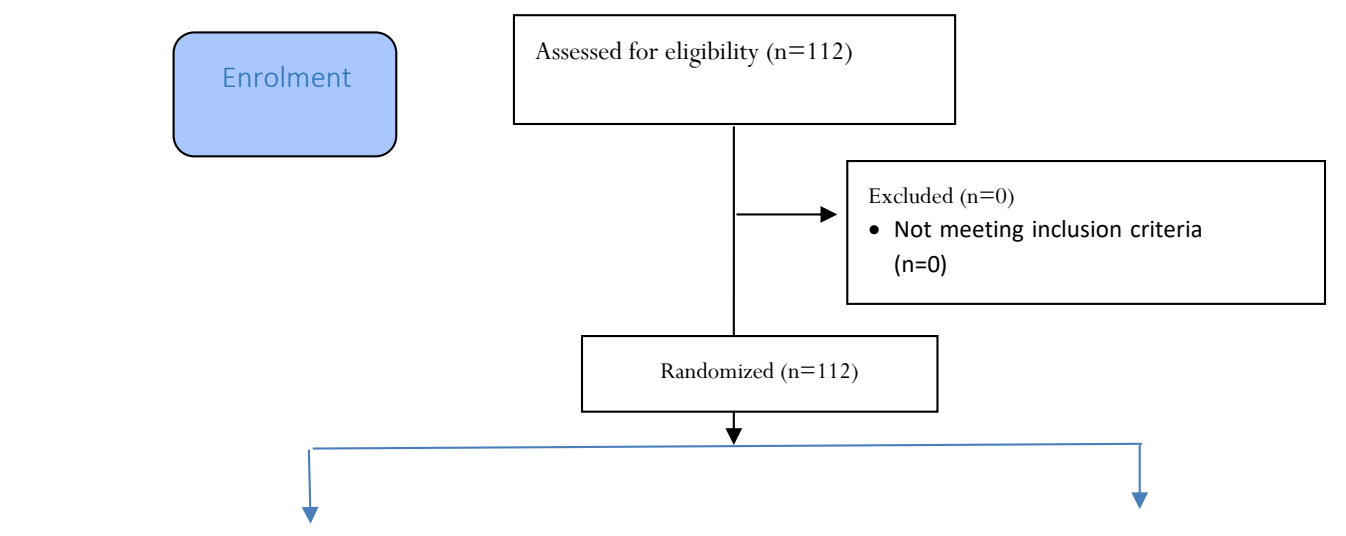

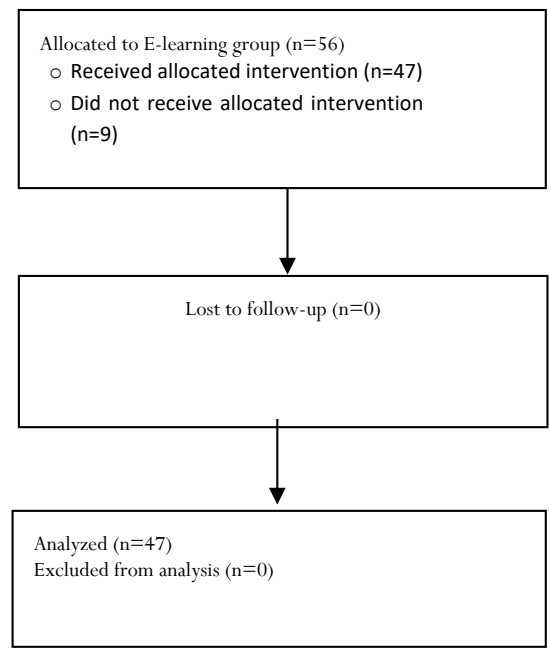

Figure 1. The flow diagram of the study

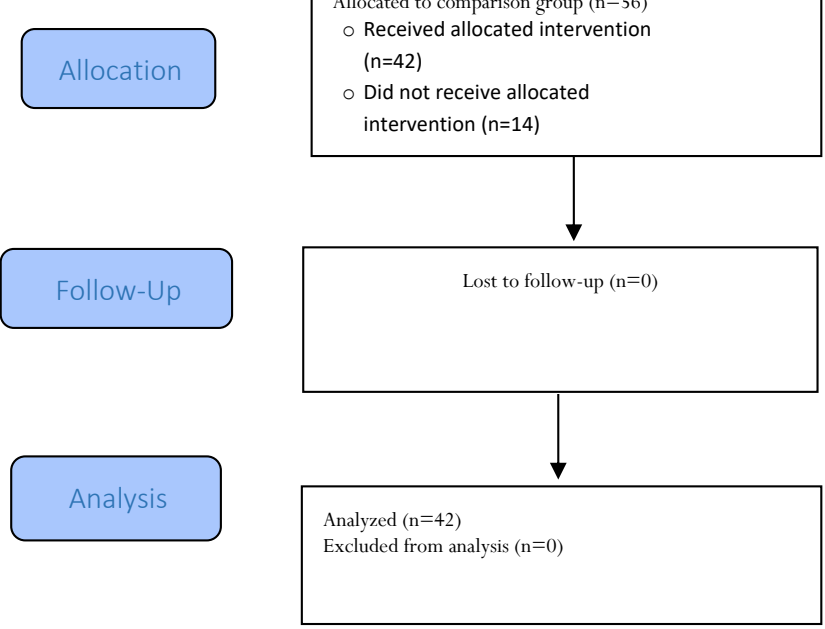

Client- Centered Nursing Care 
the study instrument. The data obtained from 42 participants (34 emergency nurses \& 8 nursing managers) in the comparison group and 47 participants (35 emergency nurses \& 12 nursing managers) in the e-learning group were included in the final analysis (Figure 1).

There were no significant differences between the study groups regarding participants' characteristics ( $\mathrm{P}>0.05$; Table 1).

The Independent Samples t-test results suggested that the pre-test mean scores of PS culture and overall perceptions of PS, organizational learning/continuous im- provement, feedback and communication about errors, non-punitive response to error, teamwork across hospital departments, and hospital handoffs and transitions dimensions in the e-learning group were significantly less than those in the comparison group $(\mathrm{P}<0.05)$. The ANCOVA was used for between-group comparisons, using the post-test mean scores of PS culture, adjusted for their corresponding pre-test mean values. The relevant results revealed no significant differences between the study groups in the post-test mean scores of frequency of events reported, hospital management support for PS, and staffing dimensions ( $\mathrm{P}>0.05)$. The post-test mean score of PS culture and its elements in the e-learning

Table 1. Between-group comparisons respecting the study participants' characteristics

\begin{tabular}{|c|c|c|c|c|}
\hline \multirow{2}{*}{\multicolumn{2}{|c|}{ Characteristics }} & \multicolumn{2}{|c|}{ No.(\%) } & \multirow{2}{*}{ Test Results } \\
\hline & & E-Learning & Comparison & \\
\hline \multirow{2}{*}{ Gender } & Male & $7(14.9)$ & $15(35.7)$ & \multirow{2}{*}{$\begin{array}{c}\chi^{2}=5.167 ; d f=1 \\
P=0.23\end{array}$} \\
\hline & Female & $40(85.1)$ & $27(64.3)$ & \\
\hline \multirow{2}{*}{ Age (y) } & Mean $\pm S D$ & $33.42 \pm 7.70$ & $35.54 \pm 7.37$ & \multirow{2}{*}{$\begin{array}{c}t=0.454 ; d f=86 \\
P=0.651\end{array}$} \\
\hline & Range & $24-53$ & $24-53$ & \\
\hline \multirow{3}{*}{ Marital status } & Single & $17(36.2)$ & $12(28.6)$ & \multirow{3}{*}{$\begin{array}{l}\text { Fisher's Exact test } \\
\qquad P=0.502\end{array}$} \\
\hline & Married & $30(63.8)$ & 29(69) & \\
\hline & Divorced & $0(0)$ & $1(2.4)$ & \\
\hline \multirow{2}{*}{ Educational level } & Bachelor's & $41(83.2)$ & $36(85.7)$ & \multirow{2}{*}{$\begin{array}{c}\chi^{2}=0.44 ; d f=1 \\
P=0.834\end{array}$} \\
\hline & Master's & $6(12.8)$ & $6(14.3)$ & \\
\hline \multirow{4}{*}{ Occupational status } & Permanent & $25(53.2)$ & $23(54.8)$ & \multirow{4}{*}{$\begin{array}{c}\chi^{2}=6.155 ; d f=3 \\
P=0.104\end{array}$} \\
\hline & Conditional permanent & $2(4.2)$ & $7(16.7)$ & \\
\hline & Post-graduation service & $13(27.7)$ & $5(11.9)$ & \\
\hline & Other & $7(14.9)$ & $7(16.7)$ & \\
\hline \multirow{2}{*}{ Work shift } & Morning & $5(10.6)$ & $3(7.1)$ & \multirow{2}{*}{$\begin{array}{c}\chi^{2}=0.331 ; d f=1 \\
P=0.565\end{array}$} \\
\hline & Rotating & $42(89.4)$ & $39(92.9)$ & \\
\hline \multirow{2}{*}{$\begin{array}{c}\text { Clinical work experi- } \\
\text { ence }(y)\end{array}$} & Mean $\pm S D$ & $10.21 \pm 7.81$ & $12.21 \pm 7.07$ & \multirow{2}{*}{$\begin{array}{c}t=0.331 ; d f=87 \\
P=0.211\end{array}$} \\
\hline & Range & $25-1$ & 29-1 & \\
\hline \multirow{2}{*}{$\begin{array}{l}\text { Work experience in } \\
\text { emergency room (y) }\end{array}$} & Mean $\pm S D$ & $4.51 \pm 4.81$ & $4.19 \pm 3.43$ & \multirow{2}{*}{$\begin{array}{c}t=-0.362 ; d f=82.816 \\
P=0.719\end{array}$} \\
\hline & Range & $19-1$ & $15-1$ & \\
\hline \multirow{2}{*}{$\begin{array}{l}\text { Managerial work } \\
\text { experience }(y)\end{array}$} & Mean $\pm S D$ & $6.92 \pm 4.53$ & $8.37 \pm 4.98$ & \multirow{2}{*}{$\begin{array}{c}t=0.687 ; d f=19 \\
P=0.501\end{array}$} \\
\hline & Range & $13-1$ & $15-2$ & \\
\hline \multirow{4}{*}{$\begin{array}{l}\text { Organizational } \\
\text { position }\end{array}$} & Nurse & $35(74.5)$ & $34(81)$ & \multirow{4}{*}{$P=0.853$} \\
\hline & Head nurse & $1(2.1)$ & $1(2.4)$ & \\
\hline & Supervisor & $10(21.3)$ & $6(14.3)$ & \\
\hline & Hospital nursing manager & $1(2.1)$ & $1(2.4)$ & \\
\hline \multirow{2}{*}{$\begin{array}{l}\text { History of receiving } \\
\text { PS-related } \\
\text { education }\end{array}$} & Yes & $20(42.6)$ & $17(40.5)$ & \multirow{2}{*}{$\begin{array}{c}\chi^{2}=0.039 ; d f=1 \\
P=0.843\end{array}$} \\
\hline & No & $27(57.4)$ & $25(59.5)$ & \\
\hline \multirow{2}{*}{$\begin{array}{l}\text { History of nursing } \\
\text { error }\end{array}$} & Yes & $5(10.6)$ & $1(2.4)$ & \multirow{2}{*}{$P=0.207$} \\
\hline & No & $42(89.4)$ & $41(97.6)$ & \\
\hline
\end{tabular}


Table 2. Within- and between-group comparisons respecting the mean scores of PS culture and its dimensions

\begin{tabular}{|c|c|c|c|c|}
\hline \multirow{2}{*}{\multicolumn{2}{|c|}{$\begin{array}{c}\text { Groups } \\
\text { PS Culture \& Its Dimensions }\end{array}$}} & \multicolumn{2}{|c|}{ Mean $\pm S D$} & \multirow{2}{*}{ Test Results } \\
\hline & & \multirow{2}{*}{$\begin{array}{c}\text { E-learning } \\
57.97 \pm 35.77\end{array}$} & \multirow{2}{*}{$\frac{\text { Control }}{62.50 \pm 30.86}$} & \\
\hline Teamwork within & Before & & & $t=0.635 ; d f=87 ; P=0.527$ \\
\hline departments & After & $88.82 \pm 23.77$ & $69.64 \pm 31.00$ & $F=15.560 ; P<0.001 ; \eta^{2}=0.153$ \\
\hline \multicolumn{2}{|l|}{ Test results } & $t=4.98 ; d f=46 ; P<0.001$ & $t=-2.913 ; d f=41 ; P=0.006$ & - \\
\hline \multicolumn{2}{|l|}{ Mean differences } & $30.85 \pm 42.41$ & $7.14 \pm 15.89$ & $t=-3.413 ; d f=87 ; P=0.001$ \\
\hline \multirow{2}{*}{$\begin{array}{l}\text { Supervisor/manager } \\
\text { expectations and ac- } \\
\text { tions promoting PS }\end{array}$} & Before & $39.89 \pm 31.12$ & $51.78 \pm 28.89$ & $t=1.861 ; d f=87 ; P=0.66$ \\
\hline & After & $79.25 \pm 29.17$ & $52.97 \pm 29.32$ & $F=35.331 ; P<0.001 ; \eta^{2}=0.291$ \\
\hline \multicolumn{2}{|l|}{ Test results } & $t=-7.128 ; d f=46 ; P<0.001$ & $t=-0.573 ; d f=41 ; P=0.570$ & - \\
\hline \multicolumn{2}{|l|}{ Mean differences } & $39.36 \pm 37.85$ & $1.19 \pm 13.47$ & $t=-6.190 ; d f=87 ; P<0.001$ \\
\hline \multirow{2}{*}{$\begin{array}{l}\text { Organizational } \\
\text { learning/continuous } \\
\text { improvement }\end{array}$} & Before & $21.27 \pm 35.72$ & $42.85 \pm 36.28$ & $t=2.824 ; d f=87 ; P=0.006$ \\
\hline & After & $61.70 \pm 39.91$ & $43.65 \pm 38.59$ & $F=24.88 ; P<0.001 ; \eta^{2}=224$ \\
\hline \multicolumn{2}{|l|}{ Test results } & $t=-6.746 ; d f=46 ; P<0.001$ & $t=-0.330 ; d f=41 ; P=0.743$ & - \\
\hline \multicolumn{2}{|l|}{ Mean differences } & $40.42 \pm 41.08$ & $0.79 \pm 15.59$ & $t=-5.882 ; d f=87 ; P<0.001$ \\
\hline \multirow{2}{*}{$\begin{array}{l}\text { Hospital management } \\
\text { support for PS }\end{array}$} & Before & $17.70 \pm 30.96$ & $32.53 \pm 36.43$ & $\mathrm{t}=2.072 ; \mathrm{df}=87 ; \mathrm{P}=0.041$ \\
\hline & After & $37.58 \pm 38.45$ & $38.88 \pm 39.58$ & $F=2.334 ; P=0.130 ; \eta^{2}=0.026$ \\
\hline \multicolumn{2}{|l|}{ Test results } & $t=-3.659 ; d f=46 ; P=0.001$ & $t=-1.947 ; d f=41 ; P=0.058$ & - \\
\hline \multicolumn{2}{|l|}{ Mean differences } & $19.85 \pm 37.20$ & $6.34 \pm 21.13$ & $t=-2.072 ; d f=87 ; P=0.041$ \\
\hline \multirow{2}{*}{$\begin{array}{l}\text { Feedback and commu- } \\
\text { nication about errors }\end{array}$} & Before & $39 \pm 33.56$ & $61.11 \pm 37.47$ & $t=2.935 ; d f=87 ; P=0.004$ \\
\hline & After & $75.88 \pm 29.24$ & $69.84 \pm 33.58$ & $F=8.800 P=0.004 \eta^{2}=0.93$ \\
\hline \multicolumn{2}{|l|}{ Test results } & $t=-6.758 ; d f=46 ; P<001.0$ & $t=-2.553 ; d f=41 ; P=0.014$ & - \\
\hline \multicolumn{2}{|l|}{ Mean differences } & $36.87 \pm 37.58$ & $22.152 \pm 8.73$ & $t=-4.239 ; d f=87 ; P<0.001$ \\
\hline \multirow{2}{*}{$\begin{array}{l}\text { Frequency of events } \\
\text { reported }\end{array}$} & Before & $17.02 \pm 25.88$ & $22.22 \pm 30.94$ & $t=0.854 ; d f=80.320 ; P=0.395$ \\
\hline & After & $19.14 \pm 25.76$ & $28.57 \pm 31.72$ & $F=1.818 ; P=0.181 ; \eta^{2}=0.021$ \\
\hline \multicolumn{2}{|l|}{ Test results } & $t=-0.684 ; d f=46 ; P=0497$ & $t=-2.238 ; d f=41 ; P=0.031$ & - \\
\hline \multicolumn{2}{|l|}{ Mean differences } & $2.12 \pm 21.31$ & $6.34 \pm 18.38$ & $t=1.003 ; d f=86.901 ; P=0.319$ \\
\hline \multirow{2}{*}{$\begin{array}{c}\text { Overall perceptions } \\
\text { of PS }\end{array}$} & Before & $24.46 \pm 23.01$ & $47.61 \pm 23.30$ & $t=4.710 ; d f=87 ; P<0.001$ \\
\hline & After & $63.29 \pm 19.40$ & $56.54 \pm 23.46$ & $F=13.941 ; P<0.001 ; \eta^{2}=0.139$ \\
\hline \multicolumn{2}{|l|}{ Test results } & $t=-10.253 ; d f=46 ; P<0.001$ & $t=-3.048 ; d f=41 ; P=0.004$ & - \\
\hline \multicolumn{2}{|l|}{ Mean differences } & $38.82 \pm 25.96$ & $8.92 \pm 18.98$ & $t=-6.138 ; d f=87 ; P<0.001$ \\
\hline \multirow{2}{*}{$\begin{array}{c}\text { Communication open- } \\
\text { ness }\end{array}$} & Before & $11.34 \pm 24.35$ & $13.49 \pm 22.15$ & $t=0.433 ; d f=87 ; P=0.666$ \\
\hline & After & $42.55 \pm 34.54$ & $21.42 \pm 28.34$ & $F=14.988 ; P<0.001 ; \eta^{2}=0.148$ \\
\hline Test results & & $t=-6.503 ; d f=46 ; P<0.001$ & $t=-2.354 ; d f=41 ; P=0.023$ & - \\
\hline Mean differences & & $31.20 \pm 32.89$ & $7.93 \pm 21.85$ & $t=-3.881 ; d f=87 ; P<0.001$ \\
\hline Teamwork across hospi- & Before & $25.53 \pm 31.91$ & $33.33 \pm 27.97$ & $t=1.220 ; d f=87 ; P=0.226$ \\
\hline tal departments & After & $81.38 \pm 26.81$ & $43.45 \pm 33.61$ & $F=57.536 ; P<0.001 ; \eta^{2}=0.401$ \\
\hline Test results & & $t=-10.470 ; d f=46 ; P<0.001$ & $t=-3.571 d f=41 ; P=0.001$ & - \\
\hline Mean differences & & $55.85 \pm 36.56$ & $10.11 \pm 18.36$ & $t=-7.319 ; d f=87 ; P<0.001$ \\
\hline & Before & $17.02 \pm 18.13$ & $17.26 \pm 26.18$ & $t=0.051 ; d f=87 ; P=0.960$ \\
\hline 1118 & After & $32.97 \pm 29.53$ & $23.21 \pm 32.38$ & $F=3.582 ; P=0.062 ; \eta^{2}=0.04$ \\
\hline Test results & & $t=-3.630 ; d f=46 ; p=0.001$ & $\mathrm{t}=-2.231 ; \mathrm{df}=41 ; \mathrm{P}=0.031$ & - \\
\hline Mean differences & & $15.95 \pm 30.13$ & $5.95 \pm 17.29$ & $t=-1.891 \mathrm{df}=87 ; \mathrm{P}=0.062$ \\
\hline
\end{tabular}




\begin{tabular}{|c|c|c|c|c|}
\hline \multirow{2}{*}{\multicolumn{2}{|c|}{$\begin{array}{c}\text { Groups } \\
\text { PS Culture \& Its Dimensions }\end{array}$}} & \multicolumn{2}{|c|}{ Mean $\pm S D$} & \multirow{2}{*}{ Test Results } \\
\hline & & \multirow{2}{*}{$\frac{\text { E-learning }}{26.59 \pm 28.26}$} & \multirow{2}{*}{$\frac{\text { Control }}{42.85 \pm 28.30}$} & \\
\hline Hospital handoffs and & Before & & & $t=2.707 ; d f=87 ; P=0.008$ \\
\hline transitions & After & $91.48 \pm 20.37$ & $61.90 \pm 27.18$ & $F=43.473 ; P<0.001 ; \eta^{2}=0.336$ \\
\hline Test results & & $t=-13.223 ; d f=46 ; P<0.001$ & $t=-4.318 d f=41 ; P<0.001$ & - \\
\hline Mean difference & & $33.64 \pm 64.89$ & $19.04 \pm 28.58$ & $t=-6.947 ; d f=86.793 ; P<0.001$ \\
\hline \multirow{2}{*}{$\begin{array}{l}\text { Nonpunitive response } \\
\text { to error }\end{array}$} & Before & $4.96 \pm 18.36$ & $12.69 \pm 23.22$ & $t=1.79 ; d f=77.927 ; P=0.008$ \\
\hline & After & $41.13 \pm 34.89$ & $16.66 \pm 27.79$ & $F=21.821 ; P<0.001 ; \eta^{2}=0.202$ \\
\hline Test results & & $t=-7.160 ; d f=46 ; P<0.001$ & $t=-1.094 ; d f=41 ; P=0.281$ & - \\
\hline Mean difference & & $36.17 \pm 34.63$ & $3.96 \pm 23.51$ & $t=-5.070 ; d f=87 ; P<0.001$ \\
\hline \multirow{2}{*}{ Total PS } & Before & $25.23 \pm 18.59$ & $36.68 \pm 15.41$ & $t=3.142 ; d f=87 ; P=0.002$ \\
\hline & After & $59.6 \pm 16.03$ & $43.89 \pm 17.8$ & $F=64.202 ; P<0.001 ; \eta^{2}=0.427$ \\
\hline Test results & & $t=-13.194 ; d f=46 ; P<0.001$ & $t=-5.654 ; d f=41 ; P<0.001$ & - \\
\hline Mean difference & & $34.36 \pm 17.85$ & $7.20 \pm 8.26$ & $t=-9.027 ; d f=87 ; P<0.001$ \\
\hline
\end{tabular}

group was significantly greater than that of the comparison group $(\mathrm{P}<0.05$; Table 2$)$.

Within-Group comparisons, using the Paired-Samples t-test data demonstrated that, except for the frequencyof-events-reported dimension, the post-test mean scores of PS culture and its other elements in the e-learning group were significantly greater than their corresponding pre-test values $(\mathrm{P}<0.001)$. Except for the supervisor/ manager expectations and actions promoting PS, organizational learning/continuous improvement, hospital management support for PS, and non-punitive response to error dimensions, the post-test mean score of PS culture and its other elements in the comparison group was significantly greater than their corresponding pre-test values $(\mathrm{P}<0.05$; Table 2$)$.

The Independent Samples t-test results revealed that, except for the staffing and frequency-of-events-reported dimensions, pre-test, post-test differences in the mean scores of PS culture and its elements in the intervention group were significantly greater than those in the control group $(\mathrm{P}<0.05$; Table 2$)$.

\section{Discussion}

This study assessed the effects of e-learning on PS culture among emergency nurses. E-Learning significantly improved PS culture and all its components, except for the frequency-of-events-reported dimension. The positive effects of e-learning were mainly due to using audiovisual materials (Sheikhaboumasoudi et al. 2018) and the easy accessibility of e-learning materials at any time and place (Meredith et al. 2018). E-Learning helps learners personally control the pace of their learning. This is because it requires no physical presence in a classroom (Pham et al. 2019). The e-learning program in this study provided nurses with the opportunity to frequently review educational materials, answer evaluation questions, and receive relevant feedback.

Consistent with our findings, a prior study reported that compared with the lecture method, e-learning presented greater positive effects on attitudes towards nosocomial infection control among the administrative staff of several hospitals in Tehran (Hashemiparast et al. 2016). Another study found that e-learning positively improved knowledge among medical students and its effects were sustained beyond one year (Gaupp et al. 2019). A study in Iran highlighted the significant positive effects of elearning through provided PDF files using the Telegram application on nursing students' knowledge, attitudes, and practices related to preventing medication errors (Pourteimour \& Jasemi 2018).

Another study found that an online educational intervention promoted blame-free attitudes toward nurses who reported their errors and improved the error reporting rate and PS culture among Jordanian nurses (AbuAlRub \& Abu Alhijaa 2014). Contrary to our findings, a study in Iran reported that face-to-face education was more effective than CD-based training in improving PS culture among hospital nurses (Mahmodi Shan et al. 2019). Another study found lecture-based education more effective than e-learning in improving knowledge about nosocomial infection control among the administrative staff of several hospitals in Iran (Hashemiparast et al. 2016).

The positive effects of e-learning on PS culture among emergency nurses in the present study can be attribut- 
ed to several factors. One factor may be the inclusion of nursing managers in the study. Improved PS culture among nursing managers in the study might have positively affected PS culture in the study setting.

The obtained data suggested the insignificant effects of e-learning on the staffing and frequency-of-eventsreported dimensions of PS culture. However, this study overlooked measuring annual error reporting numbers in the hospital. This finding may be because nurses avoid error reporting due to a concern on disciplinary measures and employment loss, blame, unfamiliarity with error reporting procedures, or their lack of knowledge about the importance of error reporting (Jember et al. 2018). Staffing is a management issue that a training program cannot directly address. Due to the shortage of nurses, it is necessary to prioritize teamwork and anticipate a suitable combination of different categories of nurses to achieve PS. Besides, education about the importance and the procedures of error reporting, a safe and supportive organizational environment is necessary to error reporting and reduce the number of errors (Azarabad et al. 2018).

One of the study limitations was the non-random allocation of participants to the study groups. This was practiced to prevent between-group information leakage. This study was conducted in two rural hospitals in Qazvin, which may limit the generalizability of the findings. The long-term effects of e-learning were not assessed. Additional studies should be conducted to assess the sustainability of e-learning's impact on PS culture in hospital settings.

\section{Conclusion}

This study found that, compared with a traditional lecture format, e-learning was more effective in improving PS culture among emergency room nurses. E-Learning is less expensive than face-to-face education and enables learners to access educational materials at any time and place. It can be used as an effective method for providing in-service training to nurses. A major advantage of e-learning is not necessitating the physical presence of learners in a certain place at a specific time. It can thus be used to provide in-service training during epidemics and pandemics, like the current coronavirus pandemic without exposing learners to the risk of infection. Education about e-learning is recommended for nursing managers and hospital supervisors to familiarize them with this educational resource and increase its use for in-service training. Our e-learning intervention presented no significant effect on the frequency of errors reported. Nursing managers and hospital supervisors should improve nurses' un- derstanding of the importance of error reporting, and create a supportive environment to encourage them to report their errors without the fear of negative consequences. We recommend studies directed at developing effective interventions that increase the frequency of reported errors.

\section{Ethical Considerations}

\section{Compliance with ethical guidelines}

The Ethics Committee of Iran University of Medical Sciences, Tehran approved this study, (Code: IR.IUMS. REC.1398.132). Permission for the study was also obtained from the Research and Technology Administration of Qazvin University of Medical Sciences, Qazvin, Iran. The participants received clear information about the aim of the study, the confidentiality of their data, and their freedom to voluntarily withdraw from the study. Informed consent was obtained from all participants.

\section{Funding}

This project was financially supported by the Research and Technology Administration of Iran University of Medical Sciences, Tehran. This article was extracted from a MSN. thesis of the second author in the Department of Emergency Nursing, School of Nursing and Midwifery, Iran University of Medical Sciences, Tehran.

\section{Authors' contributions}

All authors equally contributed to preparing this article.

Conflict of interest

The authors declared no conflicts of interest.

\section{References}

AbuAlRub, R. F. \& Abu Alhijaa, E. H., 2014. The impact of educational interventions on enhancing perceptions of patient safety culture among Jordanian senior nurses. Nursing Forum, 49(2), pp 139-50. [DOI:10.1111/nuf.12067]

Alswat, K., et al. 2017. Improving patient safety culture in Saudi Arabia (2012-2015): Trending, improvement and benchmarking BMC Health Services Research, 17(1), p. 516. [DOI:10.1186/s12913017-2461-3]

Amiri, M., Khademian, Z. \& Nikandish, R., 2018. The effect of nurse empowerment educational program on patient safety culture: A randomized controlled trial. BMC Medical Education, 18(1), p. 158 [DOI:10.1186/s12909-018-1255-6]

Aparicio, M., Bacao, F. \& Oliveira, T., 2016. An e-learning theoretical framework. Educational Technology E Society, 19(1), pp. 292-307. https://www.jstor.org/stable/jeductechsoci.19.1.292 
Azarabad, S., et al. 2018. Frequency, causes and reporting barriers of nursing errors in the operating room students. Research in Medical Education, 10(2), pp. 18-27. [DOI:10.29252/ rme.10.2.18]

Bagheri, I., et al. 2021. [Evaluation of medication errors from the perspective of nurses in the ICUs of Yazd City (Persian)]. Journal of Shahid Sadoughi University of Medical Sciences, 29(3), pp. 3588-98. [DOI:10.18502/ssu.v29i3.6203]

Barteit, S, et al. 2020. Evaluation of e-learning for medical education in low-and middle-income countries: A systematic review. Computers $\mathcal{E}$ Education, 145, p. 103726. [DOI:10.1016/j. compedu.2019.103726]

Boamah, S. A., et al. 2018. Effect of transformational leadership on job satisfaction and patient safety outcomes. Nursing Outlook, 66(2), pp. 180-9. [DOI:10.1016/j.outlook.2017.10.004]

Bodur, S. \& Filiz, E., 2010. Validity and reliability of Turkish version of Hospital Survey on Patient Safety Culture and perception of patient safety in public hospitals in Turkey. BMC Health Services Research, 10(1), p. 28. [DOI:10.1186/1472-6963-10-28]

Campione, J. \& Famolaro, T., 2018. Promising practices for improving hospital patient safety culture. The Joint Commission Journal on Quality and Patient Safety, 44(1), pp. 23-32. [DOI:10.1016/j.jcjq.2017.09.001]

Chan, B. \& Cochrane, D., 2016. Canadian Institute for Health Information (CIHI), Canadian Patient Safety Institute. Measuring Patient Harm in Canadian Hospitals. With What can be done to improve patient safety? https://secure.cihi.ca/free_products/ cihi_cpsi_hospital_harm_en.pdf

Chan, B. \& Cochrane, D., 2016. Measuring patient harm in Canadian Hospitals [Internet]. Cited 31 August 2021, https: / / secure.cihi.ca/free_products/cihi_cpsi_hospital_harm_en.pdf

Cohen, J., 2013. Statistical power analysis for the behavioral sciences. New York: Routledge. [DOI:10.4324/9780203771587]

Elmontsri, M, et al. 2017. Status of patient safety culture in Arab countries: A systematic review. BMJ Open, 7(2), p. e013487. [DOI:10.1136/bmjopen-2016-013487]

Gaupp, R., et al. 2019. Long-term effects of an e-learning course on patient safety: A controlled longitudinal study with medical students. PloS One, 14(1), p. e0210947. [DOI:10.1371/journal.pone.0210947]

González-López, J. J., Hernández-Martínez, P. \& Muñoz-Negrete, F. J., 2017. Medical errors and patient safety in Ophthalmology. Archivos de la Sociedad Española de Oftalmologia, 92(7), pp. 299-301. [DOI:10.1016/j.oftal.2017.01.009]

Hashemiparast, M. S., et al. 2016. [Comparing E-learning and lecture-based education in control of nosocomial infections (Persian)]. Journal of Payavard Salamat, 10(3), pp. 230-8. http:// payavard.tums.ac.ir/article-1-6055-en.html

Hogden, A., Churruca, K. \& Bierbaum, M., 2017. Safety culture assessment in health care: A review of the literature on safety culture assessment modes [Internet]. Cited 31 August 2021, https://www.safetyandquality.gov.au/sites/default/files/ migrated/Safety-Culture-Assessment-in-Health-Care-A-review-of-the-literature-on-safety-culture-assessment-modes.pdf

Jember, A., et al. 2018. Proportion of medication error reporting and associated factors among nurses: A cross sectional study. BMC Nursing, 17, p. 9. [DOI:10.1186/s12912-018-0280-4]
Lahti, M., Hätönen, H. \& Välimäki, M., 2014. Impact of e-learning on nurses' and student nurses' knowledge, skills, and satisfaction: A systematic review and meta-analysis. International Journal of Nursing Studies, 51(1), pp. 136-49. [DOI:10.1016/j. ijnurstu.2012.12.017

Lambrou, P., et al. 2015. Professional environment and patient safety in emergency departments. International Emergency Nursing, 23(2), pp. 150-5. [DOI:10.1016/j.ienj.2014.07.009]

Lawati, M. H., et al. 2018. Patient safety and safety culture in primary health care: A systematic review. BMC Family Practice, 19(1), p. 104. [DOI:10.1186/s12875-018-0793-7]

Lawton, R., et al. 2017. Can patient involvement improve patient safety? A cluster randomised control trial of the Patient Reporting and Action for a Safe Environment (PRASE) intervention. BMJ Quality \& Safety, 26(8), pp. 622-31. [DOI:10.1136/ bmjqs-2016-005570]

Källberg, A. S., et al. 2017. Physicians' and nurses' perceptions of patient safety risks in the emergency department International Emergency Nursing, 33, pp. 14-9. [DOI:10.1016/j. ienj.2017.01.002]

Keis, O., et al. 2017. Online or face-to-face instruction? A qualitative study on the electrocardiogram course at the University of Ulm to examine why students choose a particular format. BMC Medical Education, 17(1), p. 194. [DOI:10.1186/s12909017-1053-6]

Mahmodi Shan, G., et al. 2019. Effect of in-person and e-training on nurse managers' perception of patient safety culture in hospitals of the Golestan Province, Iran. Journal of Clinical and Basic Research, 3(1), pp. 34-9. [DOI:10.29252/jcbr.3.1.34]

Meddings, J., et al. 2017. Evaluation of the association between Hospital Survey on Patient Safety Culture (HSOPS) measures and catheter-associated infections: Results of two national collaborative. BMJ Quality \& Safety, 26(3), pp. 226-35. [DOI:10.1136/bmjqs-2015-005012]

Meredith, P., et al. 2018. Preparing mental health professionals for new directions in mental health practice: Evaluating the sensory approaches e-learning training package. International Journal of Mental Health Nursing, 27(1), pp. 106-15. [DOI:10.1111/inm.12299]

Mohebbi Far, R., et al. 2015. [Studying patient safety culture from the viewpoint of staffs in educational hospitals in Tehran City (Persian)]. Journal of Health and Safety at Work, 5(1), pp. 57-64. http://jhsw.tums.ac.ir/article-1-5243-en.html

Mollazadeh, H., et al. 2014. [Comparing the effect of education by lecture and multimedia software on learning of fundamental of nursing in nursing students (Persian)]. Journal of North Khorasan University of Medical Sciences, 6(1), pp. 151-9. [DOI:10.29252/jnkums.6.1.151]

Nasiri, M., et al. 2015. [Comparing the effects of lecture and electronic educational methods on nursing students' knowledge and attitude towards electroconvulsive therapy (Persian)] Educational Development of Judishapur, 5(4), pp. 321-30. https:/ / edj.ajums.ac.ir/article_79717.html

Nordin, A., et al. 2020. Patient safety culture change over timehealth care staffs' perceptions. Open Journal of Nursing, 10(3), pp. 320-39. [DOI:10.4236/ojn.2020.103022]

O'Connell, K. J., et al. 2018. Incident reporting to improve patient safety: The effects of process variance on pediatric patien 
safety in the emergency department. Pediatric Emergency Care, 34(4), pp. 237-42. [DOI:10.1097/PEC.0000000000001464]

Pakzad, N., et al. 2016. [A comparison of the effect of virtual and lecture-based patient safety education on patient safety culture among nurses (Persian)]. Qom University of Medical Sciences Journal, 10(9), pp. 27-34. http://journal.muq.ac.ir/ article-1-1329-fa.html

Pham, L., et al. 2019. Does e-learning service quality influence e-learning student satisfaction and loyalty? Evidence from $\mathrm{Vi}$ etnam. International Journal of Educational Technology in Higher Education, 16, p. 7. [DOI:10.1186/s41239-019-0136-3]

Pourteimour, S., Hemmati Maslakpak, M. \& Jasemi, M., 2018. [The effect of e-learning on the knowledge, attitude and practice of nursing students about the prevention of drug errors in the pediatric unit (Persian)]. Journal of Urmia and Nursing and Midwifery Faculty, 16(1), pp. 12-21. http://unmf.umsu.ac.ir/ article-1-3441-fa.html

Reis, C. T., Paiva, S. G. \& Sousa, P., 2018. The patient safety culture: A systematic review by characteristics of hospital survey on patient safety culture dimensions. International Journal for Quality in Health Care, 30(9), pp. 660-77. [DOI:10.1093/intqhe/ mzy080]

Rice, H. E., et al. 2018. Building a safety culture in global health: Lessons from Guatemala. BMJ Global Health, 3(2), p. e000630. [DOI:10.1136/bmjgh-2017-000630]

Rockville, W., et al. 2016. AHRQ Hospital Survey on Patient Safety Culture: User's Guide. Rockville, MD: Agency for Healthcare Research and Quality (AHRQ). https://www. ahrq.gov/sops/qualitypatient-safety/patientsafetyculture/ hospital/index.html

Sheikhaboumasoudi, R., et al. 2018. Improving nursing students' learning outcomes in fundamentals of nursing course through combination of traditional and e-learning methods. Iranian Journal of Nursing and Midwifery Research, 23(3), pp. 217-21. [DOI:10.4103/ijnmr.IJNMR_79_17]

Shorey, S., et al. 2018. Blended learning pedagogy designed for communication module among undergraduate nursing students: A quasi-experimental study. Nurse Education Today, 61, pp. 120-6. [DOI:10.1016/j.nedt.2017.11.011]

Sin, B., et al. 2018. The feasibility and impact of prospective medication review in the emergency department. Journal of Pharmacy Practice, 31(1), pp. 22-8. [DOI:10.1177/0897190017696948]

Slawomirski, L., Auraaen, A. \& Klazinga, N., 2017. The economics of patient safety: Strengthening a value-based approach to reducing patient harm at national level. OECD Health Working Papers, No. 96, OECD Publishing, Paris. [DOI:10.1787/5a9858cd-en]

Stang, A., et al. 2018. Safe care for pediatric patients: A scoping review across multiple health care settings. Clinical Pediatrics, 57(1), pp. 62-75. [DOI:10.1177/0009922817691820]

Vincent, C. 2011. Patient Safety, Hoboken, New Jersey: Wiley. https://www.google.com/books/edition/Patient_Safety/ $\mathrm{CbJwsamhVdoC?hl=en \& gbpv=0}$

Wilkerson, A., Boals, A. \& Taylor, D. J., 2012. Sharpening our understanding of the consequences of insomnia: The relationship between insomnia and everyday cognitive failures. Cognitive Therapy and Research, 36(2), pp. 134-9. [DOI:10.1007/ s10608-011-9418-3]
World Health Organization (WHO), 2015. e-Learning for undergraduate health professional education: A systematic review in forming a radical transformation of health workforce development [Internet]. Cited 31 August 2021, https://apps.who.int/iris/ handle/10665/330089

World Health Organization (WHO), 2019. World Health Organization's 10 facts on patient safety [Internet]. Cited 31 August 2021, https://www.iapo.org.uk/news/2018/nov/6/worldhealth-organizations-10-facts-patient-safety

Zhao, X., et al. 2017. Survey and analysis of patient safety culture in a county hospital. Family Medicine and Community Health, 5(4), pp. 299-310. [DOI:10.15212/FMCH.2017.0137] 
This Page Intentionally Left Blank 